\title{
CRIAÇÃO "DO DIREITO" E CRIAÇÃO "DE DIREITOS": A DIFERENÇA ENTRE INTERPRETAÇÃO E ATIVISMO JUDICIAL E RESPECTIVAS CONSEQUÊNCIAS
}

\author{
Zélia Luiza Pierdoná ${ }^{1}$ \\ Verbena Duarte Brito de Carvalho
}

\section{Resumo:}

Objetiva-se, com o presente trabalho, apontar as diferenças entre o resultado de interpretação judicial e o ativismo judicial, cujas soluções são, respectivamente, a criação do Direito e a criação de direitos. As expressões estão diferentemente grafadas para vinculá-las a comportamentos distintos: "do Direito", refere-se à regra extraída da ordem jurídica, enquanto "de direitos", diz respeito a direitos subjetivos (reais ou ideais). O método utilizado foi o dialético, a partir da revisão bibliográfica e pesquisa jurisprudencial, com enfoque na criação jurisdicional, cujo resultado permite constatar as diferentes realidades decorrentes da escolha do juiz, quando da prestação jurisdicional.

Palavras-chave: hermenêutica; criação do direito; criação de direitos; ativismo judicial; separação de poderes.

\section{CREATION OF THE LAW AND CREATION OF THE RIGHTS: THE DIFFERENCE BETWEEN INTERPRETATION AND JUDICIAL ACTIVISM AND THEIR CONSEQUENCES}

\begin{abstract}
:
This paper aims to point out the differences between the result of judicial interpretation and judicial activism, whose solutions are, respectively, the creation of law and the creation of rights. The expressions are differently spelled to link them to different behaviors: "from law" refers to the rule extracted from the legal order, while "from rights" refers to subjective rights (real or ideal). The method used was the dialectic, from the literature review and jurisprudential research, focusing on jurisdictional creation, whose result allows us to see the different realities arising from the choice of the judge, when the court.
\end{abstract}

Keywords: hermeneutics; creation of law; rights creation; judicial activism; separation of powers.

\section{Introdução}

O presente trabalho tem por escopo apontar as diferenças entre o que se conhece como o resultado de interpretação judicial das leis e o ativismo judicial, cujas soluções são, respectivamente, a criação do Direito e a criação de direitos.

\footnotetext{
${ }^{1}$ Professora do Programa de Pós-Graduação em Direito Político e Econômico da Universidade Presbiteriana Mackenzie

${ }^{2}$ Mestranda do Programa de Pós-Graduação em Direito Político e Econômico da Universidade Presbiteriana Mackenzie
} 
Inicialmente deve ser esclarecido que os vocábulos estão diferentemente grafados para vinculá-los a comportamentos distintos: os vocábulos "do Direito", com a letra inicial maiúscula, se referem à regra extraída da ordem jurídica, do sistema ou conjunto de normas de um determinado país, enquanto o emprego dos vocábulos "de direitos", com a inicial minúscula, diz respeito a direitos subjetivos (reais ou ideais).

A opção do juiz pelo ativismo pode violar vários princípios constitucionais, dentre os quais, o princípio democrático de direito e o princípio da separação de poderes, preconizados, respectivamente, nos artigos $1^{\circ}$ e $2^{\circ}$ da Constituição de 1988 , o que se pretende demonstra no trabalho.

O método utilizado foi o dialético, a partir da revisão bibliográfica e pesquisa jurisprudencial, com enfoque na criação jurisdicional, cujo resultado permite constatar os efeitos de uma decisão ativista.

\section{Hermenêutica jurídica}

A hermenêutica é a ciência da interpretação. Quando o direito é aplicado por um órgão jurídico, ele precisa se valer da interpretação para fixar o sentido e o alcance da norma jurídica. Até porque o ordenamento jurídico deve ser coerente e traduzir uma unidade sistemática.

A interpretação deve levar em conta que a ordem jurídica é escalonada, sendo a Constituição a norma de escalão superior, dela se originando todas as demais normatividades do arcabouço jurídico do Estado. Interpretar é, pois, desvendar a relação entre as normas escalonadas e, quando se cuida de interpretação judicial, se o caso concreto a elas se subsume.

Evidentemente esta operação intelectual não pertence às ciências exatas, havendo inevitavelmente indeterminações, tanto no ato de criação das leis quanto no da aplicação do Direito. Há, portanto, espaço para criação do direito.

Com efeito, a vontade do legislador pode não corresponder às palavras expressas na lei. Essa indeterminação tanto pode decorrer do fato de uma mesma palavra poder ter diversos significados, cabendo ao aplicador escolher um, entre vários, quanto em razão de mais de uma norma pretender regular simultaneamente uma mesma situação jurídica.

Kelsen, referindo-se a interpretação assim assevera:

(...) uma operação mental que acompanha o processo da aplicação do Direito no seu progredir de um escalão superior para um escalão inferior. Na hipótese em que 
geralmente se pensa quando se fala de interpretação da lei, deve responder-se à questão de saber qual o conteúdo que se há de dar à norma individual de uma sentença judicial ou de uma resolução administrativa, norma essa a deduzir da norma geral da lei na sua aplicação a um caso concreto (KELSEN, 2006, p. 387).

A atividade do intérprete fica presa as normas constitucionais, visto que a Constituição inaugura o ordenamento jurídico. Ele não sai para buscar outros elementos, senão aqueles que embasam a própria Constituição. Quando constrói, é nela, e nos princípios que a informam, bem como na normatividade que dela deriva, que o intérprete procura, para os casos obscuros, uma solução não prevista de forma expressa. Esta função de construção interpretativa permite que se desdobre a Constituição e todo o ordenamento jurídico, construindo um direito logicamente contido nas disposições de todo o referido ordenamento.

Assim, a interpretação, aí incluída a interpretação constitucional, é também criação, pois o intérprete não pode ater-se exclusivamente ao texto, a letra da lei, isolando-a das outras partes do ordenamento jurídico, originadas da Constituição, bem como dos princípios e valores superiores da Justiça, da Ética e da Moral que a informa, da natureza das coisas, da evolução e das necessidades sociais, da vida e do processo histórico. O que, de forma alguma, implica criação de direitos subjetivos não previstos.

\section{A interpretação como atividade criadora do Direito}

Como visto acima, não se pode negar o cunho criador da interpretação normativa pelo juiz. E há uma necessidade cada vez maior do uso, pelo Judiciário, da interpretação criadora do Direito, que extrai de todo o ordenamento a norma aplicável ao caso concreto, cuja costura, muitas vezes de várias leis e princípios, traduz a atividade criadora do juiz.

Até porque criação e interpretação não são, em essência, atividades tão distintas.

Evidenciam fases de um mesmo processo. A criação está contida no complexo processo interpretativo. A tarefa de captar o sentido, o alcance e o significado de dispositivos constitucionais e outros que deles derivam e comum a ambos os expedientes, ate mesmo naqueles casos onde inexiste normatividade expressa, ou naquelas hipóteses de antinomia, nas quais duas normas contraditórias, emanadas de autoridades competentes num mesmo âmbito normativo, colidem, sem que se possa saber qual delas devera ser aplicada ao caso concreto. 
Tanto em hipótese de lacuna, como em caso de antinomia jurídica, o juiz não pode se furtar da prestação jurisdicional. Apreciando o caso sub judice, a todo o instante, também o interpreta, buscando a significação dos conceitos jurídicos, diante da eventual ambiguidade do texto.

Tal mister, por diversas razões, apanhadas com perspicácia por Mauro Cappelletti (1999), por certo exigiu o rompimento da concepção justiniana da interpretação das leis, pela qual o papel do juiz se resumia a ser a "boca da lei”.

Segundo o mencionado autor, a ampliação desmedida da atuação legislativa, em especial na área de políticas sociais, fenômeno que surgiu no pós-guerra, com o aparecimento do welfare state, colocou o Estado como agente de promoção social e organizador da economia, e teve como efeito uma modificação correlata na atuação do Judiciário, cujo papel foi ampliado sobremaneira.

De fato, se antes do fenômeno o papel do legislador se voltava a regras de conduta, a função do juiz era a de proteger e reprimir, respectivamente, as regras e quem delas se desviasse. Sob o welfare state o âmbito de atuação das leis e intensidade das intervenções públicas se amplia, em especial para acomodações institucionais.

A atuação legislativa exacerbada redundou em normas que se valiam cada vez mais de princípios, outorgada ao Poder Executivo a tarefa de especificar as leis, em normatividade subordinada. Em relação à citada normatividade, alerta Cappelletti que "originalmente um 'estado legislativo', transformou-se, assim, e continua permanentemente se transformando, em 'estado administrativo', na verdade em 'estado burocrático', não sem o perigo de sua perversão em “estado de polícia” (CAPPELLETTI 1999, p. 39).

Nesse contexto, com a necessidade crescente da interpretação criativa, e espaço para um certo grau de discricionariedade do aplicador da lei, o papel do juiz criador do Direito e do ativista (e no presente trabalho se frisa a diferença), ganha amplitude. Na segunda hipótese, como forma de construção de um sistema de controle (político) da normatividade dos dois Poderes políticos.

Em decorrência, o controle de cada um dos Poderes se resolve pela observância da doutrina dos freios e contrapesos (check and balance), adotada pela Constituição de 1988, com previsão de vários mecanismos para tal. Assim, o manejo dos mencionados mecanismos tornaria desnecessária a atuação do juiz como ativista e criador de direitos, sob tal justificativa. 
O único freio de que dispõe o Judiciário contra os Poderes Legislativo e Executivo resume-se, no nosso ordenamento jurídico, no controle de constitucionalidade de leis e atos administrativos, incluídas as ações constitucionais, inclusive as que se dirigem à inconstitucionalidade por omissão, como o mandado de injunção, a ação direta de inconstitucionalidade por omissão, bem como as ações coletivas (quando propostas pelo Ministério Público, em razão dos efeitos erga omnes da decisão judicial), não se podendo confundir o manejo dos instrumentos do check and balance, com o ativismo judicial.

\section{Diferenças entre criação "do Direito" e criação "de direitos"}

A criação do Direito pelo juiz pressupõe a existência de lacunas jurídicas. Tem sua previsão de uso no art. $4^{\circ}$ do Decreto-Lei 4.657/42, com a redação dada pela Lei 12.376/2010.

O mencionado artigo dispõe: “Quando a lei for omissa, o juiz decidirá o caso de acordo com a analogia, os costumes e os princípios gerais de direito". Ou seja, o citado dispositivo legal indica a necessidade da costura criadora no ordenamento.

Entretanto, não se pode confundir omissão da lei com ausência de previsão legal. A primeira decorre quase sempre do uso inadequado da técnica legislativa. A segunda, da ausência de vontade política do legislador em abarcar determinada situação fática no âmbito da proteção legal. Conceder direitos na segunda hipótese traduz claro ativismo judicial.

A diferença entre os tipos de lacunas é esclarecida por Norberto Bobbio (1997) na sua obra Teoria do Ordenamento Jurídico.

$\mathrm{Na}$ referida obra, o autor, que pertencia à corrente jusfilosófica denominada "escola analítica", esclarece que não há espaço para lacunas no direito. Pode haver lacuna em determinada norma, mas o ordenamento jurídico é uno, e a lacuna é preenchida por métodos de interpretação, dentro da própria lei ou fora dela, dentro do ordenamento.

Por outro lado, a ausência de previsão legal pode até não ser politicamente satisfatória, o que, todavia, não significa que não seja uma solução jurídica. É o que o autor denomina de "lacuna ideológica". Nesse sentido esclarece Bobbio:

Uma vez que essas lacunas derivam não da consideração do ordenamento jurídico como ele é, mas da comparação entre o ordenamento jurídico como ele é e como deveria ser, foram chamadas de "ideológicas", para distingui-las daquelas que eventualmente se encontrassem no ordenamento jurídico como ele é, e que se podem chamar de "reais". Podemos também enunciar a diferença deste modo: as lacunas ideológicas são lacunas de iure condendo (de direito a ser estabelecido), as lacunas reais são de iure condito (do direito já estabelecido) (BOBBIO, 1997, P. 140). 
Justamente aí reside a diferença entre criação "do Direito" e criação "de direitos" pelo juiz, sendo esta última o que, no presente trabalho, se denomina de "ativismo judicial".

Sobre ativismo judicial Elival da Silva Ramos (2010, p. 116) assim pondera:

\begin{abstract}
Ao se fazer menção ao ativismo judicial, o que se está referir é a ultrapassagem das linhas demarcatórias da função jurisdicional, em detrimento da função legislativa, mas, também, da função administrativa e, até mesmo, da função de governo. Não se trata do exercício desabrido da legiferação (ou de outra função não jurisdicional), que, aliás, em circunstâncias bem delimitada, pode vir a ser deferido pela própria Constituição aos órgãos superiores do aparelho judiciário, e sim da descaracterização da função típica do Poder Judiciário, com incursão insidiosa sobre o núcleo essencial de funções constitucionalmente atribuídas a outros Poderes" (pp. 116 e117).
\end{abstract}

O mencionado autor, sustenta, ainda, que "a observância da separação dos Poderes importa, dentre diversos outros consectários, na manutenção dos órgãos do Judiciário nos limites da função jurisdicional que lhes é confiada e para cujo exercício foram estruturados" (RAMOS, 2010, p. 117).

No mesmo sentido DIMOULIS (2012, p. 267) assevera que "a Constituição não autoriza o Judiciário a decidir se as opções dos demais poderes são boas ou ruins ou se haveria melhores". Para ele, a única questão que cabe aos julgadores "é se certa decisão é inconstitucional ou ilegal" e, se não for inconstitucional ou ilegal, o juiz deve aceitar a “solução dada pelo poder que possui a competência primária de cada caso".

Segundo o referido autor, nas hipóteses em que não há comprovação da violação da lei ou da Constituição, “o juiz 'ativista' excede sua competência e ofende o princípio democrático que designa o legislador como representante do povo e, portanto, como primeiro concretizador da Constituição" (DIMOULIS, 2012, p. 286).

A título de ilustração da diferenciação entre interpretação criativa do Direito e criação de direitos (ativismo judicial), cita-se a crescente judicialização da saúde, cujas demandas quase sempre giram em torno de pedidos para que o Estado se encarregue da compra de medicação X ou Y, específica para tratamento do requerente, algumas, inclusive, usadas ainda em caráter experimental e de elevados custos, sem registro na Agência Nacional de Vigilância Sanitária (ANVISA).

Os argumentos principais dos que pretendem obter medicações e tratamentos, via ação judicial, giram em torno do direito à saúde, ao princípio da universalidade e o da dignidade humana. No entanto, a universalidade não significa impedir a restrição da amplitude do direito porque a ideia de universalidade só faz sentido sob o foco do princípio da 
igualdade, nos termos do art. $196^{3}$ da Constituição. O que justifica a inclusão de todos, sem qualquer distinção, nas politicas de saúde do Estado e o reconhecimento de que todos são iguais.

Assim, se todos merecem tratamento igualitário por parte do Estado quando este elabora e implementa as politicas de saúde, tal não ocorre quando, em ação individual, cuja sentença tem eficácia limitada, circunscrita às partes, garante o direito à obtenção de medicação X ou Y.

De fato, em que pese a Constituição elencar no art $6^{\circ}$, e reiterar no art. 196, o direito à saúde como um direito fundamental e universal, e também a Lei $\mathrm{n}^{\circ}$ 8.080/90, em seu art. $2^{\circ}$, estabelecer que a saúde é direito fundamental do ser humano, devendo o Estado prover as condições indispensáveis ao seu pleno exercício, não há outras leis especificando as doenças e/ou medicações passíveis de serem fornecidas gratuitamente, exceto no âmbito do SUS, com base no art. $6^{\circ}$ da Lei $n^{\circ} 8.080 / 90$.

Ao contrário, desde 2011 há vedação expressa ao pagamento, ressarcimento ou o reembolso de medicamento, produto e procedimento clínico ou cirúrgico experimental, ou de uso, se não autorizado pela Agência Nacional de Vigilância Sanitária - ANVISA.

Assim, não há lacuna normativa, mas sim uma "lacuna ideológica", a qual está em consonância com o princípio da seletividade e distributividade na prestação dos benefícios e serviços, previsto no inciso III do parágrafo único do art. 194 da Constituição.

O referido princípio deve ser considerado enquanto não há possibilidade de efetivar o princípio da universalidade, previsto no inciso I do mesmo dispositivo constitucional. Em outras palavras, rumo à universalização, o legislador deve estabelecer etapas para efetivação dos direitos de seguridade social (saúde, previdência e assistência), o que também atende ao princípio da progressividade, previsto no Pacto Internacional dos Direitos Econômico, Sociais e Culturais, do qual o Brasil é signatário.

A progressividade, referida no pacto, considera a necessidade de recursos públicos imprescindíveis para a efetivação dos direitos sociais, o que está de acordo com os preceitos constitucionais, em especial os relacionados aos direitos componentes do sistema de seguridade social.

3 Art. 196. A saúde é direito de todos e dever do Estado, garantido mediante políticas sociais e econômicas que visem à redução do risco de doença e de outros agravos e ao acesso universal e igualitário às ações e serviços para sua promoção, proteção e recuperação. 
Isso porque há previsão expressa em relação à seletividade, mencionada acima (art. 194, parágrafo único, III, da Constituição), bem como da necessidade de custeio prévio para a criação, majoração e extensão dos direitos relacionados à saúde, à previdência e à assistência social ( $\$ 5^{\circ}$ do art. 195, também da Constituição).

Portanto, o que Bobbio denomina "lacuna ideológica", decorre, ao menos em relação aos direitos sociais, da implementação progressiva, acima mencionada.

Assim, em que pese a alínea "d", do inciso I do art. $6^{\circ}$ da Lei $n^{\circ}$ 8.080/90 incluir no campo de atuação do SUS a assistência terapêutica, inclusive a farmacêutica, o arcabouço normativo, quanto à produção e ao fornecimento de medicamentos, indica que apenas os relacionados na RENAME (Portaria 2012/2008) devem ser fornecidos pelo Poder Público.

Diante da referida situação, o juiz intérprete queda-se sem resposta positiva a este tipo de demanda, se o medicamento não estiver relacionado no RENAME e sequer registrado na ANVISA, indeferindo o pleito.

Já o juiz ativista, condena o Estado a fornecê-la, sem atentar para o custo do medicamento, e tampouco à vedação legal estabelecida no art. 19-T, da Lei no 8.080/90, ou para os princípios norteadores da seguridade social, em especial o da seletividade e o do custeio prévio, acima mencionados.

Constatando várias situações como a acima exemplificada, Pierdoná (2006) conclui que as demandas judiciais individuais não são os meios adequados para concretização dos direitos à saúde, que devem ser implementados tão somente por politicas públicas estabelecidas a partir da gestão democrática, preceituada no art. 194, paragrafo único, VII da Constituição.

Aduz a mencionada autora que "em não havendo politicas sociais, as demandas judiciais devem ser intentadas com o objetivo de determinar que elas sejam fixadas ou que seja suprida a omissão, na hipótese de necessidade de criação por meio de lei. Portanto, as demandas não podem ser individuais" (PIERDONÁ, 2006, p. 6052).

Vale lembrar que o exemplo acima se presta tão somente para ilustrar o explanado acima, uma vez que a controvérsia sobre o tema foi recentemente decidida, em solução "ativista mitigada", pelo Supremo Tribunal Federal, que obrigou o Estado a fornecer medicamentos, ainda que não relacionados na RENAME, mas desde que registrados na ANVISA. 
O Plenário do referido Tribunal decidiu, no dia 22/05/2019, que o Estado não pode ser obrigado a fornecer medicamento experimental ou sem registro na Agência Nacional de Vigilância Sanitária (ANVISA), salvo em casos excepcionais.

A decisão foi tomada, por maioria de votos, no julgamento do Recurso Extraordinário (RE) 657718, com repercussão geral reconhecida. O Ministro Alexandre de Moraes ressaltou que o artigo 19-T da Lei $\mathrm{n}^{\circ}$ 8.080/1990, veda, em todas as esferas de gestão do SUS, o pagamento, o ressarcimento ou o reembolso de medicamento experimental ou de uso não autorizado pela ANVISA, e que o dispositivo não é inconstitucional.

No voto-vista, o referido Ministro asseverou que "não se trata de negar direito fundamental à saúde. Trata-se de analisar que a arrecadação estatal, o orçamento e a destinação à saúde pública são finitos” (RE 657718, 2019).

Assinalou ainda que a excessiva judicialização da matéria não tem sido uma boa solução, uma vez que "para cada liminar concedida, os valores são retirados do planejamento das políticas públicas destinadas a toda coletividade".

O ministro reconheceu que “(...) senão, não teremos universalidade, mas seletividade, onde aqueles que obtêm uma decisão judicial acabam tendo preferência em relação a toda uma política pública planejada" (RE 657718, 2019).

Outro exemplo para explicitar a diferença entre o juiz intérprete e o juiz ativista e ficando nos direitos de seguridade social, para os quais se aplicam os princípios acima mencionados, da seletividade e do custeio prévio, pode ser extraído da decisão do Supremo Tribunal Federal, no julgamento da Reclamação no 4.374/PE (julgada em conjunto com os Recursos Extraordinários nº 580.963/PR e 567.985-3/MT, com repercussão geral).

Na referida decisão o Supremo Tribunal Federal autorizou que cada juiz ou membro do tribunal avalie, no caso concreto, o atendimento do requisito miserabilidade, o que tem ocasionado decisões discrepantes, já que tem prevalecido o subjetivismo do julgador, em detrimento de critérios objetivos, previstos pelo legislador.

No julgamento, o Supremo Tribunal Federal reconheceu a competência do legislador para selecionar as etapas de concretização do benefício assistencial (previsto no art. 203, V, da Constituição), em razão do equilíbrio econômico-orçamentário.

Apesar disso, os ministros decidiram que o juiz poderá analisar, no caso concreto, a situação de miserabilidade, em desacordo com o preceito do art. 203, V da Constituição, o qual estabelece a competência do legislador para fixar os requisitos necessários à concessão 
do citado benefício. Além disso, o Supremo Tribunal Federal não considerou os princípios da seletividade e do custeio prévio.

$\mathrm{Na}$ mesma linha, em relação à previdência social, cita-se a decisão do Superior Tribunal de Justiça, no Recurso Especial $\mathrm{n}^{\circ}$ 1.720.805-RJ (rito dos recursos especiais repetitivos), que determinou a extensão do adicional de $25 \%$ da aposentadoria por invalidez, para as outras espécies de aposentadoria. Observa-se que o mencionado Tribunal também não respeitou a seleção feita pelo legislador infraconstitucional e, com isso, não considerou o princípio da seletividade.

O princípio do custeio também não foi observado, embora na decisão tenha sido registrado que não haveria necessidade de considerá-lo, uma vez que a extensão estaria relacionada à assistência e não à previdência. Entretanto, deve ser ressaltado que o $\S 5^{\circ}$ do art. 195 da Constituição é expresso no sentido de que "nenhum benefício ou serviço da seguridade social poderá ser criado, majorado ou estendido sem a correspondente fonte de custeio total".

Portanto, para a criação, majoração ou extensão de direitos relacionados às três áreas integrantes da seguridade social deve ser observado o custeio prévio.

Por certo o juiz intérprete não verá lacuna na lei, a exigir interpretação criativa do Direito, mas sim uma lacuna ideológica. Reconhecerá que tal solução não é politicamente satisfatória, o que não significa de modo algum que não seja uma solução jurídica. Já o juiz ativista, diante de casos semelhantes aos relatados acima, concederá a proteção, preenchendo as lacunas ideológicas, o que é de competência do Poder Legislativo ou Executivo, violando assim a separação de poderes, pedra de toque da democracia.

Em que pese se referirem ao fenômeno como se tratasse de interpretação constitucional, e que neste trabalho se denomina ativismo, Bastos e Britto (1982) observaram a forte tendência deste tipo de atuação:

\footnotetext{
Por conseguinte, e acentuada a repercussão desse elevado teor ideológico de que se impregna a realidade politica, no processo de interpretação das normas constitucionais. Estas, para a apreensão do seu mais íntimo e fiel significado, passam a solicitar o aporte complementar de elementos extra-sistemáticos, em certa medida, hospedados muito mais na dinâmica dos fatos que na estática da positivação formal. E num grau de intensidade bem maior que o suplicado pelas normas de direito comum, que não desenham os contornos do poder politico e não cuidam da repartição de seu exercício entre os Órgão supremos do Estado, ou entre as pessoas politicas de base territorial (BASTOS E BRITTO, 1982, p.17).
}

Patrick Devlin (1976), citado por Cappelletti (1999), aponta como uma importante debilidade do direito judiciário a incompetência institucional da magistratura para agir como 
força criadora de direitos, porque faltam aos tribunais os necessários instrumentos e conhecimento de como o direito se realiza. Sustenta ele que:

\begin{abstract}
Os juízes, segundo esse entendimento, não têm possibilidade de desenvolver pessoalmente o tipo de investigações requeridas para uma obra criativa, que não podem se limitar às leis e aos precedentes, e envolvem problemas complexos e dados sociais, econômicos e políticos; não dispõem sequer dos recursos, inclusive financeiros, mediante os quais os parlamentos, comissões legislativas e ministérios estão em condições de encarregar terceiros para efetuar pesquisas que, frequentemente, nem os legisladores e administradores saberiam desenvolver por si mesmos. [...] Ressalta-se, assim, o problema não menos grave da efetiva realização das decisões: quando os juízes tomam certas decisões de caráter político lato sensu têm a sua disposição escassos instrumentos para lhes assegurar a execução, e geralmente são carentes de qualquer possibilidade de observar e controlar, caso por caso, tal execução e seus efeitos (CAPPELLETTI, 1999, p.87-88).
\end{abstract}

Assim, também por esse motivo é inadequada a criação de direitos pelo juiz, pois conforme adverte Bobbio (2004), ainda que a linguagem dos direitos tenha uma grande função prática, de emprestar uma força particular as reivindicações dos movimentos que demandam para si e para os outros a satisfação de necessidade, "ela se torna enganadora se obscurecer ou ocultar a diferença entre o direito reivindicado e o direito reconhecido e protegido" (BOBBIO, 2004, p. 11).

\title{
4. Os princípios democráticos em jogo: separação de poderes e igualdade.
}

Antes de tratar sobre os princípios mais afetados pelo ativismo judicial, necessário delimitar o que aqui se entende por princípios, o que se faz na lição de Alexy (1993). Para o autor:

Princípios são normas que ordenam que algo seja realizado na maior medida possível, dentro das possibilidades jurídicas e reais existentes. Portanto, os princípios são mandados de otimização, que estão caracterizados pelo fato de que podem ser cumpridos em diferentes graus, e que a medida devida de seu cumprimento não só depende das possibilidades reais, como também das jurídicas (...). De outro lado, as regras são normas que só podem ser cumpridas ou não. Se uma regra e valida, então deve-se fazer exatamente o que ela exige, nem mais nem menos. Portanto, as regras contem determinações no âmbito do fático e juridicamente possível (ALEXY, 1993, p. 86-87).

O princípio da separação de poderes foi idealizado por Montesquieu, inspirado na teoria esposada por John Locke, e preconiza que os Poderes Legislativo, Executivo e Judicial devem ser atribuídos a pessoas diferentes, sem, contudo, pontuar rigorosa separação entre as funções. Para ele, deveria existir verdadeira harmonia entre eles, o que se conseguiria pela 
atribuição conjunta e indivisível de três órgãos, quer dizer, a co-soberania de três órgãos políticos.

O princípio foi formalmente adotado pela Declaração Universal dos Direitos do Homem e do Cidadão, proclamada em Versalhes, em 1789, a qual estabelece, no art. 16 que "A sociedade em que não esteja assegurada a garantia dos direitos nem estabelecida a separação dos poderes não tem Constituição”. Considerado como um dogma, a ponto de ser positivado na Declaração, o princípio objetivava afastar o despotismo do ancien régime e influenciou vários países.

De se ressaltar que o referido princípio, mais do que um dogma, é a verdadeira pedra de toque da democracia. Mesmo em suas origens, não foi concebido como um modelo fechado, onde cada poder exerceria única e exclusivamente sua função. Menos ainda hodiernamente. Todas as constituições contemporâneas atribuírem funções típicas e atípicas aos poderes constituídos.

A função atípica é o resultado do exercício de atribuições que não lhe são primordialmente próprias, e que os Poderes Legislativo, Executivo e Judiciário tem agregado, de forma cada vez mais crescentes, as suas competências de origem, até como decorrência da transformação do Estado liberal em Estado do bem-estar social (welfare state).

De fato, o exercício de funções atípicas, em especial pelos poderes políticos, torna-se cada vez maior na medida em que o Estado Democrático transforma-se em Estado Social, pela exacerbação dos encargos da intervenção legislativa, transferida ao Poder Executivo e seus órgãos derivados, e toda uma série de entidades e agências, com funções normativas secundárias. Evidentemente que a citada exacerbação refletiu-se também no Poder Judiciário.

As funções atípicas são manejadas como mecanismos que a doutrina denomina de "freios e contrapesos" (check and balance), e estão estabelecidos em diversos artigos da Constituição. Assim, partindo-se da ideia de que o juiz ativista assume função típica do Poder Legislativo, na omissão deste, porém em lacuna ideológica, é patente o abuso de competência atípica fora do quadro do check and balance.

A criação de direitos, como exercício de ativismo judicial, traduz uma postura nitidamente intervencionista, que se afasta dos ideais democráticos, já que o princípio da separação de poderes, como acima mencionado, tem estreita vinculação com o Estado democrático de direito, verdadeira pedra de toque da democracia. 
O princípio da igualdade, por sua vez, é também afetado diretamente pelo ativismo judicial. Este princípio, verdadeiro dogma da democracia, abre a Carta de 1789: “Art.1. ${ }^{\circ}$ Os homens nascem e são livres e iguais em direitos" e é princípio norteador de várias outras declarações de direitos, tendo passado a ser reproduzido em praticamente todas as constituições após a Revolução Francesa.

Ao reconhecer um direito que não existe no quadro do ordenamento jurídico, apesar de eventualmente ser ideal (no entender do magistrado), em uma ação individual, o juiz atua na criação de direitos para aquele demandante, com exclusão de todos os demais, ainda que em situações fáticas idênticas, em razão da eficácia da sentença atingir tão somente as partes, restando ferido o princípio da igualdade.

\section{Conclusão}

Não se nega ao juiz o papel de criador do Direito. Todavia, fora do quadro normativo constitucional e do ordenamento jurídico, não há espaço para criação de direitos, pois o juiz ativista maneja poderes políticos que não possui, preenchendo lacunas ideológicas do ordenamento jurídico, e exercendo uma forma de controle sobre os demais poderes não previsto na Constituição.

As consequências do ativismo judicial são o preenchimento de lacunas ideológicas, pelo juiz, ou seja, criação ou extensão de hipóteses legais para situações não especificadas em lei, fazendo do juiz um legislador, o que fere princípios constitucionais caros à democracia, entre outros, o da igualdade e o da separação de poderes.

A essência dessa teoria se firma no princípio de que os três poderes que formam o Estado (legislativo, executivo e judiciário) devem atuar de forma separada, independente e harmônica, mantendo, no entanto, as características de um poder uno. A citada teoria, ressaltese, foi adotada pela grande maioria dos Estados ocidentais modernos, e estabelece a distinção entre as funções desempenhadas no âmbito de cada poder, bem como as respectivas limitações. Ou seja, nenhum poder está absolutamente livre para atuar, encontrando seu limite nos outros dois, o que a doutrina denomina de sistema de freios e contrapesos.

Dessa forma, o controle de cada um dos Poderes se resolve pela observância da doutrina dos freios e contrapesos (check and balance), adotada pela Constituição de 1988, com previsão de vários mecanismos para efetivar o mencionado controle. 
Assim, o manejo dos mencionados mecanismos tornaria desnecessária a atuação do juiz como ativista e criador de direitos, sob tal justificativa. Menos ainda em demandas judiciais individuais, sob pena de ferir o princípio mais caro à democracia: o princípio da igualdade, uma vez que a decisão criadora de direitos não terá efeitos erga omnes, e se dirigirá tão somente ao autor da ação.

\section{Referências}

ALEXY, Robert. Teoria de los derechos fundamentales. Madrid: Centro de Estudios Constitucionales, 1993;

BASTOS, Celso e BRITTO, Carlos Aires. Interpretação e aplicabilidade das normas constitucionais. São Paulo: Saraiva, 1982;

BOBBIO, Norberto. Teoria do Ordenamento Jurídico. Brasília: Editora UNB, 1982;

BOBBIO, Norberto. A Era dos Direitos. $7^{\text {a }}$ reimp. Rio de Janeiro: Elsevier, 2004;

BONAVIDES, Paulo. Curso de Direito Constitucional. 10. Ed. São Paulo: Malheiros, 1988;

BRASIL. Constituição da República Federativa do Brasil. Disponível em:

http://www.planalto.gov.br/ccivil_03/constituicao/constituicao.htm. Acesso em 30 ago. 2019;

BRASIL, Superior Tribunal de Justiça. REsp nº 1.720.805/RJ, 22.08.2018 (Ministra Regina Helena Costa - Relatora para acórdão). Disponível em:

https://ww2.stj.jus.br/processo/revista/documento/mediado/?componente=ITA\& sequencial $=1705875 \&$ num_registro $=201800206322 \&$ data $=20180926 \&$ formato $=P D F$. Acesso em 29 ago. 2019;

BRASIL, Supremo Tribunal Federal. Recurso Extraordinário RE 657718. Relator: Ministro Roberto Barroso. Disponível em:

https://portal.stf.jus.br/processos/detalhe.asp?incidente=4143144. Acesso em 28 ago. 2019;

BRASIL, Supremo Tribunal Federal, Reclamação nº 4.374/PE, 18.04.2013, Relator: Ministro Gilmar Mendes, Disponível em:

http://redir.stf.jus.br/paginadorpub/paginador.jsp?docTP=TP\&docID=4439489 . Acesso em 30 ago. 2019;

BULOS, Uadi Lamêgo. Teoria da interpretação constitucional. Rio de Janeiro: Revista de Direito Administrativo, jul./set. 1996, pp. 23-64;

CAPPELLETTI, Mauro. Juízes Legisladores? Porto Alegre: Sérgio Fabris, 1999;

DIMOULIS, Dimitri, 2012, "Além do ativismo e do minimalismo judicial no campo dos direitos fundamentais: justificação jurídica de decisões e competências”, in Neoconstitucionalismo e atividade jurisdicional: do passivismo ao ativismo judicial, José Carlos Francisco. (Org.), Del Rey, Belo Horizonte, pp. 261-277; 
DINIZ, Maria Helena. As lacunas do Direito. São Paulo: Saraiva, 1989;

FERRAZ, Octavio Luiz Motta e VIEIRA, Fabiola Sulpino. Direito a Saúde, Recursos Escassos e Equidade: Os Riscos da Interpretação Judicial Dominante. Rio de Janeiro: Revista de Ciências Sociais, Vol. 52, no 1, 2009, pp. 223 a 251;

KELSEN, Hans. Teoria Pura do Direito. São Paulo: Martins Fontes, 2006;

OMMATI, Fides. Dos freios e contrapesos entre os Poderes do Estado. Brasília: Revista de Informação legislativa, ano14 no 55, jul./set. 1977. Disponível em:

https://www2.senado.leg.br/bdsf/bitstream/handle/id/181023/000359521.pdf?sequence.

Acesso em 28 ago. 2019;

PIERDONÁ, Zélia Luiza. O ativismo judicial na seguridade social brasileira: a violação dos princípios constitucionais e a inobservância das escolhas feitas pelos Poderes Legislativo e Executivo. Católica Law Review, v. 3, p. 159-182, 2019;

PIERDONÁ, Zélia Luiza. O direito à saúde e a impossibilidade de concessão de medicamentos por decisões judiciais individuais. Publicado nos Anais do XVIII Congresso Nacional do CONPEDI, realizado em São Paulo, nos dias 04, 05, 06 e 07 de novembro de 2009. Disponível em:

http://www.publicadireito.com.br/conpedi/manaus/arquivos/anais/sao_paulo/2307.pdf.

Acesso em 29 ago. 2019;

RAMOS, Elival da Silva, 2010, Ativismo Judicial: parâmetros dogmáticos, Editora Saraiva, São Paulo. 